\title{
Betting on the underdog: the influence of social networks on vote choice
}

\author{
Annika Fredén ${ }^{1 *}$, Ludovic Rheault ${ }^{2}$ and Indridi H. Indridason ${ }^{3}$ \\ ${ }^{1}$ Political, Historical, Religious and Cultural Studies, Karlstad University, Karlstad, Sweden;, ${ }^{2}$ Political Science and Munk \\ School of Global Affairs and Public Policy, University of Toronto, Toronto, Canada and ${ }^{3}$ Political Science, University of \\ California, Riverside, CA, USA \\ ${ }^{*}$ Corresponding author. Email: Annika.Freden@kau.se
}

(Received 1 July 2019; revised 20 January 2020; accepted 20 February 2020; first published online 10 June 2020)

\begin{abstract}
People are commonly expected not to waste their vote on parties with small probabilities of being elected. Yet, many end up voting for underdogs. We argue that voters gauge the popular support for their preferred party from their social networks. When social networks function as echo chambers, a feature observed in real-life networks, voters overestimate underdogs' chances of winning. We conduct voting experiments in which some treatment groups receive signals from a simulated network. We compare the effect of networks with a high degree of homogeneity against random networks. We find that homophilic networks increase the level of support for underdogs, which provides evidence to back up anecdotal claims that echo chambers foster the development of fringe parties.
\end{abstract}

Keywords: Experimental research; elections and campaigns; voting behavior; social networks

A large body of literature assumes that voters aim to affect electoral outcomes by choosing strategically among parties large enough to gain representation. This requires somewhat accurate information about the popularity of the competitors. Many electoral contexts, however, are characterized by poor information about the likely outcome, as polls are typically conducted at the national level while legislative seats are allocated at the district level. When the usefulness or accuracy of polls is uncertain, voters are likely to rely on alternative sources of information. Their social networks represent one such option. Because networks are often characterized by homophily, one consequence is that voters are liable to form inaccurate expectations about the popularity of the competitors.

We advance that such distortions help explain why, in many elections, a sizable share of the electorate supports parties with little hope of winning a seat-parties that could be considered "underdogs". Even in an established democracy like Canada, where the plurality system is expected to generate two-party races at the district level, over 21 percent of the votes cast during the 2015 general election were for a third-party candidate. ${ }^{1}$ Similarly, in proportional representation systems, more than one in nine voters voted for parties that failed to gain representation in the 2013 Icelandic election (Indridason et al., 2017) and nearly one in six voters during the 2015 Polish election (Jasiewicz and Jasiewicz-Betkiewicz, 2016).

We propose a novel explanation for voters' willingness to support underdogs. Rather than considering this behavior an anomaly, we note that voters rarely possess the information about party

\footnotetext{
${ }^{1}$ Third-party candidates are those who are not comprised among the two front-runners in each district. Data from the Library of Parliament: https://lop.parl.ca/sites/ParlInfo/default/en_CA/ElectionsRidings/Elections (accessed December 18, 2018).

(c) The European Political Science Association 2020. This is an Open Access article, distributed under the terms of the Creative Commons Attribution licence (http://creativecommons.org/licenses/by/4.0/), which permits unrestricted re-use, distribution, and reproduction in any medium, provided the original work is properly cited.
} 
support needed to vote strategically. We represent the voter's dilemma as a coordination game in which players must draw inferences about whether a small party (the underdog) is viable enough to gain representation. We argue that voters rely on their social networks as a cheap source of information to solve their coordination problem. When networks are reinforcing-i.e., characterized by assortative mixing (also called homophily or echo chambers) (McPherson et al., 2001; Bakshy et al., 2015) - as is often observed in real-life networks, strong supporters tend to overestimate the chances of the underdog winning. We test this model using laboratory experiments in which participants are randomly assigned to a network, some of them receiving information about the political preferences of their peers. Our results support the view that network information can influence the decision to support underdogs, by affecting voter perceptions about their chances of success.

Exploring how social networks affect the vote is particularly relevant given the growing role of social media in politics, which has reemphasized an earlier body of work documenting the influence of peer networks on political behavior (Huckfeldt and Sprague, 1995; Mutz, 2006; Sinclair, 2012; Ahn et al., 2014). Not only have social media expanded the size of individuals' social networks, and the frequency and ease with which individuals interact, they have also made it easier to connect with like-minded individuals. There is ample evidence that online networks reproduce (or amplify) the assortative mixing observed in real-life networks (Colleoni et al., 2014; Bakshy et al., 2015; Eady et al., 2019). Empirical findings remain mixed, however, regarding the consequences of these "echo chambers", for instance their potential impact on the decline of deliberative politics, the fomentation of extreme ideology, and political polarization (Farrell, 2012; Lee et al., 2014; Colleoni et al., 2014; Barberá et al., 2015; Flaxman et al., 2016; Bail et al., 2018; Eady et al., 2019).

We examine whether reinforcing networks lead voters to make biased inferences about the viability of small parties. The proposed mechanism sheds light on the purported link between echo chambers and the support for fringe parties. Our findings represent a novel contribution to the literature on social networks and political behavior (e.g., Sokhey and McClurg, 2012; Bond et al., 2012; Santoro and Beck, 2017). Many studies of political networks have focused on two-party systems (e.g., Zuckerman et al., 1994; Huckfeldt and Sprague, 1995), ${ }^{2}$ where opportunities for strategic voting rarely arise, or examined network effects on other outcomes such as political participation (McClurg, 2003, 2006; Großer and Schram, 2006; Battaglini et al., 2008; Gil de Zúñiga et al., 2012; Tufekci and Wilson, 2012; Boulianne, 2015), the impact of elite communication on opinion formation (Siegel, 2009, 2013; Ahn et al., 2014), and "correct voting" (Ryan, 2011; Pietryka, 2016). We expand on this literature by focusing on vote choice, specifically in multi-party systems where voters face a different challenge in the form of coordination problems.

\section{Theoretical considerations}

We focus our attention on a setting in which voters have narrowed their possible choices to two parties. In doing so, we zero in on situations where strategic voting is possible: voters facing a choice between a preferred party with limited chances of gaining representation (the underdog), and a second preference that is viable. This scenario often occurs, e.g., in elections under proportional representation where one of two ideologically similar parties is at risk of not reaching the threshold for representation. For example, if a Portuguese voter prefers the newly-formed Alliance Party but the party is at risk of not gaining seats in her district, the voter faces a dilemma between supporting the underdog or rallying around the safer option, the Social Democratic Party. As in many real-life campaigns, we assume that each voter is uncertain about the preferences of other voters.

This decision problem can be represented as a $n$-player coordination game. The underdog has a chance of winning if enough voters coordinate on their sincere preference. On the other hand,

\footnotetext{
${ }^{2}$ A notable exception is Beck (2002), which examined support for Perot in the 1992 presidential election.
} 
Table 1. Payoff structure

\begin{tabular}{lll}
\hline & Underdog does not gain representation & Underdog gains representation \\
\hline Vote Underdog $(\mathrm{U})$ & $x_{i}$ & $c+x_{i}$ \\
Vote Safe Option $(\mathrm{S})$ & $c$ & $c+x_{i}$ \\
\hline
\end{tabular}

voting for the underdog when other voters fail to do the same implies a wasted vote-the viable second-preferred party would have done better had everyone voted for it. Table 1 presents the payoff structure for this problem. We assume that voters differ in their preference for the underdog. We denote the strength of this preference with the variable $x_{i}$, and assume it is drawn randomly from a uniform distribution. Casting a vote for a party that gains representation yields a constant payoff of $c$; in effect this is the value of not wasting one's vote. When the underdog receives enough votes to win representation (at least equal to some threshold T), the voter's total payoff is $c+x_{i}$. A voter choosing the underdog when it fails to win representation only receives a payoff of $x_{i}$. Thus, in choosing the underdog, a voter has a chance of getting the maximum payoff of $c+x_{i}$, but also risks only receiving a payoff of $x_{i}$. The voter's other option, which we refer to as the safe option, is to vote for the viable party, which guarantees a minimum payoff of $c$. We assume voters assign greater value to not wasting their vote than expressing a sincere preference, i.e., $x_{i}<c$.

This game resembles the stag hunt, a coordination game with two pure-strategy equilibria: one in which the voters coordinate on the risky option for a higher payoff $\left(x_{i}+c\right)$, and one in which the voters choose the safe option for a certain but lower payoff $(c)$. The voters in our model face the same type of coordination problem. This setup departs from a pure spatial model of candidate competition, in that it incorporates an element of expressive support while retaining the essential features of the coordination problem in the stag hunt. We do so for two reasons. First, expressive support strikes us as a reasonable motivation for voters and, in particular, supporters of parties that might be considered underdogs. Part of the rationale for supporting underdogs is to protest against the more mainstream alternatives, and there has been an upsurge in research on expressive voting of late (for an overview, see Hamlin and Jennings, 2019). Second, these payoffs provide the simplest possible formulation for the coordination problem faced by supporters of underdog parties. A first equilibrium arises in which all voters choose the safe option; switching the vote to the underdog reduces the voter's payoff from $c$ to $x_{i}$. In a second type of equilibrium, at least $T$ voters choose the underdog, where $T$ is the threshold, i.e., the number of votes needed for representation. In such scenarios, no voters can improve their payoff by modifying their decision, and players achieve a Pareto-efficient outcome $c+x_{i}$. Experimental evidence on stag hunt games suggest players tend to coordinate on the safe option (Skyrms, 2013).

Our main contribution is to consider social networks as a mechanism for equilibrium selection. If voters possess information on the preferences $x_{j}$ of individuals with whom they share connections in the network, they may use this information to infer the likelihood of coordination on the risky option. The network signals reproduce the opinions that voters in a real-life setting would observe on social media, for instance, seeing posts from friends or followers. As discussed earlier, social networks are usually not random, which may distort perceptions of the likelihood that voters will coordinate on the underdog. Our central claim is that network information is a key mechanism voters use to decide between risky and safe choices in elections. ${ }^{3}$

Building upon this discussion, we offer two hypotheses. The first concerns the influence of homophilic networks on equilibrium selection. In the presence of network signals revealing

\footnotetext{
${ }^{3}$ Our setup defines an underdog as a party that has some theoretical chance of achieving representation, albeit a marginal one. The model could be extended to situations where an underdog does not actually have a theoretical chance to win, even when all of its supporters vote sincerely.
} 


\section{To help you make a decision, the personal bonuses of two other players in your election are shown in} the blue circles.

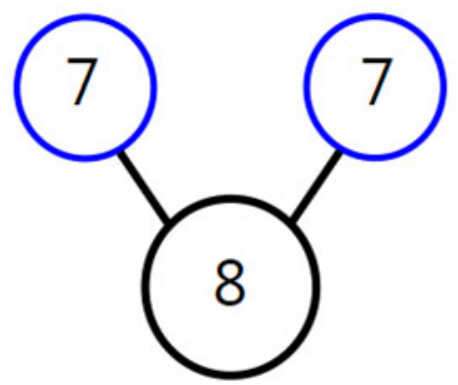

Your personal bonus

Figure 1. Information in homophily treatment.

the preferences of other voters $\left(x_{j}\right)$, we expect that a voter is more likely to coordinate on the underdog when she observes a strong preference for the candidate in her network, compared to the control condition (Hypothesis 1). In contrast, signals coming from a random network provide no cues that help solve the coordination problem. Thus, we expect no difference in behavior between voters receiving signals from a random network and where no network information is available (Hypothesis 2).

\section{Experimental design}

We designed a laboratory voting experiment in which participants choose between two parties competing in simulated elections: Party S (the Safe Option) and Party U (the Underdog). The experiment was conducted in a computer lab on May 29, 2018. We recruited 96 participants in total, 24 for each session. The participants were randomly assigned into subgroups of six voters for each election. We informed participants that the Underdog must receive at least five out of six votes to get elected. Before each election, each voter was assigned a random number (from a discrete uniform distribution ranging from 1 to 9) representing their strength of preference for the Underdog $\left(x_{i}\right)$. Thus, as the distribution of preferences and subgroups of six voters change each round, the voters face a new electorate every time they vote. We set the constant invoked in the theory section to $c=10$. The participants voted in 20 consecutive elections.

To examine the effects of social networks on coordination, we considered two network treatments along with a control condition. Each participant was randomly assigned to one condition. In the control group, participants receive no information about other voters. Participants are informed about the existence of randomized private values, but they do not observe the private values of other participants. In the first treatment group (random network), each voter observes the private values of two randomly selected peers among the six voters participating in the election. In the second treatment group (homophilic network), the network ties are reinforcing. We partition the voters so that the three participants with the highest $x_{i}$ values are grouped together, with the other three participants forming another group. Within their network, voters observe the private values of the participants who are most similar to them (see Figure 1). This simulates the phenomenon of assortative mixing, whereby voters who share similar attributes are more likely to develop network ties. The online appendix provides additional information about the experimental design, along with descriptive statistics and balance checks. 
Table 2. Cross-tabulation of the vote for the underdog, by experimental group

\begin{tabular}{lcr}
\hline & & Vote choice \\
\cline { 2 - 3 } & Safe option (S) & Underdog (U) \\
\hline Control & $79.58 \%$ & $20.42 \%$ \\
Random Network & $78.75 \%$ & $21.25 \%$ \\
Homophilic Network & $74.79 \%$ & $25.21 \%$ \\
Low Signal & $92.29 \%$ & $7.71 \%$ \\
High Signal & $57.29 \%$ & $42.71 \%$ \\
All & $76.98 \%$ & $23.02 \%$ \\
Observations & & 1920 \\
\hline
\end{tabular}

Table 3. Treatment effects (logistic regressions with cluster-robust standard errors)

\begin{tabular}{|c|c|c|c|}
\hline & \multicolumn{3}{|c|}{ Vote choice (Underdog $=1$ ) } \\
\hline & Model 1 & Model 2 & Model 3 \\
\hline Homophilic Network (Low Signal) & $\begin{array}{l}-1.178^{\star * \star} \\
(0.284)\end{array}$ & $\begin{array}{c}-0.001 \\
(0.307)\end{array}$ & $\begin{array}{c}0.078 \\
(0.291)\end{array}$ \\
\hline Homophilic Network (High Signal) & $\begin{array}{l}1.167^{\star \star \star} \\
(0.209)\end{array}$ & $\begin{array}{c}0.647^{\star} \\
(0.270)\end{array}$ & $\begin{array}{l}0.751^{\star \star} \\
(0.260)\end{array}$ \\
\hline Random Network & $\begin{array}{c}0.054 \\
(0.284)\end{array}$ & $\begin{array}{c}0.177 \\
(0.329)\end{array}$ & $\begin{array}{c}0.352 \\
(0.305)\end{array}$ \\
\hline Private Signal & & $\begin{array}{l}0.539^{\star \star \star} \\
(0.052)\end{array}$ & $\begin{array}{l}0.559^{\star \star \star} \\
(0.051)\end{array}$ \\
\hline Tolerance to Risk & & & $\begin{array}{l}0.255^{\star \star \star} \\
(0.060)\end{array}$ \\
\hline Round & $\begin{array}{l}-0.118^{\star \star \star} \\
(0.014)\end{array}$ & $\begin{array}{l}-0.148^{\star \star \star} \\
(0.016)\end{array}$ & $\begin{array}{l}-0.157^{\star \star \star} \\
(0.018)\end{array}$ \\
\hline Constant & $\begin{array}{c}-0.252 \\
(0.197)\end{array}$ & $\begin{array}{c}-3.180^{\star \star \star} \\
(0.359)\end{array}$ & $\begin{array}{c}-4.737^{\star \star \star} \\
(0.548)\end{array}$ \\
\hline Observations & 1,920 & 1,920 & 1,920 \\
\hline Participants (Clusters) & 96 & 96 & 96 \\
\hline Nagelkerke's $R^{2}$ & 0.221 & 0.402 & 0.433 \\
\hline
\end{tabular}

Notes: The table reports the output of logistic regression models computed with bootstrapped, cluster-robust standard errors, where clusters represent the participants. The base category for treatment effects is the control group. Standard errors are in parentheses. ${ }^{*} p<0.05 ;{ }^{* \star} p<0.01 ;{ }^{* \star *} p<0.001$.

\section{Findings}

We start by examining the baseline rates of support for the underdog party across experimental groups. Table 2 shows that the underdog (Party $\mathrm{U}$ ) is chosen roughly 20 percent of the time by participants assigned to the control group. This proportion increases to about 25 percent in the homophilic treatment ( $\mathrm{p}=0.12$; bootstrapped cluster-robust $\mathrm{p}$-value). However, the comparison obscures the actual effect of homophily as our treatment generates two groups of participants. The fourth and fifth rows report the same cross-tabulation, this time by contrasting the participants whose network contained the three lowest payoffs for selecting the underdog ("Low Signal") and those with the high payoffs ("High Signal"). When exposed to a network of voters who have a strong preference for the underdog, the tendency to vote for that party doubles, to 43 percent.

Conversely, when the signal received from the network indicates weaker support, participants are much more likely to select the safe option, with the overall support for the underdog dropping below 8 percent. Once private signals $\left(x_{i}\right)$ are controlled for, however, a network of players with weak preferences for the underdog does not behave differently from the control group (see Table 3 and discussion below). Our experiment also allows us to contrast reinforcing networks with random networks. The underdog vote share in the random network treatment is 21 percent, 
which is statistically indistinguishable from the control group $(\mathrm{p}=0.80)$. This is consistent with our second hypothesis.

The results support the principal contention made in this paper. When real-life social networks are composed of individuals who think alike, voters with a strong preference for an underdog party receive signals that may overstate the overall strength of support for that option. In turn, these signals increase the likelihood of voting for the underdog. Our claim is that this phenomenon is a key mechanism explaining the paradox of voters who "fail" to defect from nonviable candidates. In game-theoretic parlance, social networks serve as a tool for equilibrium selection. However, as illustrated by the strikingly different patterns between the homophilic and random treatments, the network itself provides no useful information for coordination when network connections are random. Signals need to be one-sided, as one would expect inside networks with the characteristics of echo chambers.

Table 3 reports logistic regressions of the binary decision to vote for the underdog, with clusterrobust standard errors (where clusters are the individual participants). The models include the treatment variables, in addition to a time trend. As rounds progress, the overall share of participants selecting the risky option decreases, suggesting that participants adjust their behavior after observing that the underdog rarely wins. The second model controls for the individual preference for the underdog $x_{i}$ (the private signal). The third model adds a control variable measuring the general risk preference of respondents on a 0-10 scale (Dohmen et al., 2010). These models support the conclusions outlined above. The likelihood of selecting the underdog is greater under the homophilic treatment with high signals (using the control group as a base category), everything else being equal, a result that is statistically significant at conventional levels.

The results illustrate why homophilic networks tend to benefit underdogs in the aggregate. Once the individual payoffs are taken into account (Models 2 and 3 from Table 3), the treatment effect is statistically significant only for the subgroup receiving high signals from the homophilic network. In other words, voters are equally likely to choose the safe option when their own sincere preference for the underdog is weak, regardless of whether or not they are informed of the reinforcing preferences of their network. This finding is consistent with the tendency of players to choose the safe option in stag hunt experiments (Skyrms, 2013). On the other hand, when the network brings together voters with a strong preference for the underdog, networks have a significant impact on the decision to coordinate on the risky option. In that case, we estimate the (conditional) average treatment effect, using the difference in predicted probabilities between the homophilic treatment with high signal and the control group, to be around 14 percentage points (see the appendix for an extended discussion).

\section{Concluding remarks}

We examined the impact of social networks on the support for underdogs using laboratory experiments. We expected that network information would affect evaluations of the underdog's chance of winning, in particular when a voter belongs to a reinforcing network where other voters share strong preferences for the underdog. We find clear evidence supporting the existence of such an effect. In other words, a promising explanation for people choosing to "waste" their vote on underdog candidates in real-world elections is that their social network may lead them to overestimate support for that alternative. In our experiments, the tendency to vote for underdogs is significantly higher for voters receiving signals from a reinforcing network of strong supporters, when compared to scenarios without network information and where network connections are random. Our results thus suggest that social networks have important effects on strategic voting, but these effects only arise when networks have the characteristics of echo chambers. A substantive implication for the study of democracy is that echo chambers can foster support for fringe parties, consistent with recent claims suggesting that social media may spur the growth of extremist ideologies (see, e.g., Flaxman et al., 2016). 
Supplementary material. To view supplementary material for this article, please visit https://doi.org/10.1017/psrm.2020.21.

Acknowledgments. The authors thank the Royal Swedish Academy of Sciences, Södertörn University, the Karl Staaff Foundation, the Royal Society of Arts and Sciences in Gothenburg, the Swedish Research Council (2017-02941), and the Social Sciences and Humanities Research Council of Canada for funding support. We also thank Eryk Krysowski for lab assistance. We are grateful to the reviewers and editor for helpful comments. For replication materials, visit https://oi. org/10.7910/DVN/BFLOTT. Ethics approval was obtained from the Institutional Review Board-SB of University of California, Riverside (HS 17-131).

\section{References}

Ahn TK, Huckfeldt R and Ryan JB (2014) Experts, Activists, and Democratic Politics: Are Electorates Self-Educating? Cambridge: Cambridge University Press.

Bail CA, Argyle LP, Brown TW, Bumpus JP, Chen H, Hunzaker MBF, Lee J, Mann M, Merhout F and Volfovsky A (2018) Exposure to opposing views on social media can increase political polarization. Proceedings of the National Academy of Sciences 115, 9216-9221.

Bakshy E, Messing S and Adamic LA (2015) Exposure to ideologically diverse news and opinion on Facebook. Science (New York, N.Y.) 348, 1130-1132.

Barberá P, Jost JT, Nagler J, Tucker JA and Bonneau R (2015) Tweeting from left to right: is online political communication more than an echo chamber? Psychological Science 26, 1531-1542.

Battaglini M, Morton RB and Palfrey TR (2008) Information aggregation and strategic abstention in large laboratory elections. American Economic Review 98, 194-200.

Beck PA (2002) Encouraging political defection: the role of personal discussion networks in partisan desertions to the opposition party and Perot votes in 1992. Political Behavior 24, 309-337.

Bond RM, Fariss CJ, Jones JJ, Kramer ADI, Marlow C, Settle JE and Fowler JH (2012) A 61-million-person experiment in social influence and political mobilization. Nature 489, 295.

Boulianne S (2015) Social media use and participation: a meta-analysis of current research. Information, Communication \& Society 18, 524-538.

Colleoni E, Rozza A and Arvidsson A (2014) Echo chamber or public sphere? predicting political orientation and measuring political homophily in Twitter using big data. Journal of Communication 64, 317-332.

Dohmen T, Falk A, Huffman D and Sunde U (2010) Are risk aversion and impatience related to cognitive ability? American Economic Review 100, 1238-1260.

Eady G, Nagler J, Guess A, Zilinsky J and Tucker JA (2019) How many people live in political bubbles on social media? evidence from linked survey and Twitter data. SAGE Open 9, 1-21.

Farrell H (2012) The internet's consequences for politics. Annual Review of Political Science 15, 35-52.

Flaxman S, Goel S and Rao JM (2016) Filter bubbles, echo chambers, and online news consumption. Public Opinion Quarterly 80, 298-320.

Gil de Zúñiga H, Jung $\mathbf{N}$ and Valenzuela S (2012) Social media use for news and individuals' social capital, civic engagement and political participation. Journal of Computer-Mediated Communication 17, 319-336.

Großer J and Schram A (2006) Neighborhood information exchange and voter participation: an experimental study. American Political Science Review 100, 235-248.

Hamlin A and Jennings C (2019) Expressive voting. In Roger BG, Congleton D and Voigt S (eds), The Oxford Handbook of Public Choice, Volume 1, Chapter 16. Oxford: OUP, pp. 333-350.

Huckfeldt RR and Sprague J (1995) Citizens, Politics and Social Communication: Information and Influence in an Election Campaign. Cambridge: Cambridge University Press.

Indridason IH, Önnudóttir EH, Thórisdóttir H and Hardarson ÓT (2017) Re-electing the culprits of the crisis? elections in the aftermath of a recession. Scandinavian Political Studies 40, 28-60.

Jasiewicz K and Jasiewicz-Betkiewicz A (2016) Poland. European Journal of Political Research 55, 204-215. Political Data Yearbook.

Lee JK, Choi J, Kim C and Kim Y (2014) Social media, network heterogeneity, and opinion polarization. Journal of Communication 64, 702-722.

McClurg SD (2003) Social networks and political participation: the role of social interaction in explaining political participation. Political Research Quarterly 56, 449-464.

McClurg SD (2006) The electoral relevance of political talk: examining disagreement and expertise effects in social networks on political participation. American Journal of Political Science 50, 737-754.

McPherson M, Smith-Lovin L and Cook JM (2001) Birds of a feather: homophily in social networks. Annual Review of Sociology 27, 415-444.

Mutz DC (2006) Hearing the Other Side: Deliberative Versus Participatory Democracy. Cambridge: Cambridge University Press. 
Pietryka MT (2016) Accuracy motivations, predispositions, and social information in political discussion networks. Political Psychology 37, 367-386.

Ryan JB (2011) Social networks as a shortcut to correct voting. American Journal of Political Science 55, 753-766.

Santoro LR and Beck PA (2017) Social networks and vote choice. In Victor JN, Montgomery AH and Lubell M (eds), The Oxford Handbook of Political Networks. Oxford: Oxford University Press, p. 383.

Siegel DA (2009) Social networks and collective action. American Journal of Political Science 53, 122-138.

Siegel DA (2013) Social networks and the mass media. American Political Science Review 107, 786-805.

Sinclair B (2012) The Social Citizen. Chicago: University of Chicago Press.

Skyrms B (2013) The Stag Hunt and the Evolution of Social Structure. Cambridge: Cambridge University Press.

Sokhey AE and McClurg SD (2012) Social networks and correct voting. Journal of Politics 74, 751-764.

Tufekci Z and Wilson C (2012) Social media and the decision to participate in political protest: observations from Tahrir square. Journal of communication 62, 363-379.

Zuckerman AS, Valentino NA and Zuckerman EW (1994) A structural theory of vote choice: Social and political networks and electoral flows in Britain and the United States. Journal of Politics 56, 1008-1033.

Cite this article: Fredén A, Rheault L, Indridason IH (2022). Betting on the underdog: the influence of social networks on vote choice. Political Science Research and Methods 10, 198-205. https://doi.org/10.1017/psrm.2020.21 